\title{
"ESCRIBIMOS LIBERTAD CON MANO ENCADENADA". NOTAS SOBRE UNA PINTURA REALIZADA POR AGUSTÍN IBARROLA EN LA CÁRCEL DE BURGOS
}

\author{
Noemi de Haro García ${ }^{1}$ \\ Universidad Autónoma de Madrid
}

Las pinturas realizadas clandestinamente por Agustín Ibarrola en la Prisión Central de Burgos entre 1962 y 1965 fueron expuestas por toda Europa y reproducidas en diversas publicaciones en apoyo a campañas pro-amnistía. Este artículo estudia una de estas pinturas, la única de todas ellas que se ha podido localizar hasta la fecha.

Palabras clave: Agustín Ibarrola; Conferencia de Europa occidental para la amnistía de los presos y exiliados políticos españoles; Appeal for Amnesty in Spain; Presos Políticos; Antifranquismo.

\section{"WE WRITE FREEDOM WITH CHAINED HAND". NOTES ON A PAINTING BY AGUSTÍN IBARROLA CREATED IN THE PRISON OF BURGOS}

The paintings made by Agustín Ibarrola while he was incarcerated in the Prisión Central de Burgos between 1962 and 1965 were exhibited throughout Europe and reproduced in a number of publications to support pro-amnesty campaigns. This article studies one of these paintings, the only one thus far to have been found.

Key words: Agustín Ibarrola; West European conference for Spanish political prisoners and exiles, Appeal for Amnesty in Spain; Political Prisoners, Anti-Franco movements.

Cómo citar este artículo / Citation: De Haro García, Noemí (2019): "Escribimos libertad con mano encadenada". Notas sobre una pintura realizada por Agustín Ibarrola en la cárcel de Burgos". En: Archivo Español de Arte, vol, 92, núm. 365, Madrid, pp. 83-92. https://doi.org/10.3989/aearte.2019.07.

El 28 de marzo de 1965 se celebraba en Londres la Conferencia de Europa occidental para la amnistía de los presos y exiliados políticos españoles ${ }^{2}$. Se celebró en la Georgian Room del Hotel Piccadilly y a ella acudieron delegados de once países ${ }^{3}$. También debió de asistir al encuentro un corresponsal de la agencia EFE que ridiculizaba una reunión que había "sido 'ignorada' completamente por la Prensa [sic] inglesa, anunciada sólo durante toda la semana por el periódico 'Daily Worker' y coreada por los conocidos órganos de Prensa [sic] europeos, en especial, los comunistas franceses y 'Le Monde', que daban la impresión de estar convocando una asamblea

\footnotetext{
1 noemi.deharo@uam.es / ORCID iD: http://orcid.org/0000-0001-7429-1646.

${ }^{2}$ La autora desea expresar su agradecimiento a Agustín Ibarrola, Mariluz Bellido, José Ibarrola, José Ángel Etxániz, Eileen Turner y Sir Stephen Sedley por toda su labor y por su colaboración con esta investigación. Este trabajo se ha realizado gracias a un contrato del subprograma Ramón y Cajal (RYC-2013-1288), y está vinculado al proyecto de investigación HAR2015-67059-P (MINECO-FEDER).

3 Faye, 1965: 354.
} 
extraordinaria de la O.N.U." ${ }^{4}$ No decía nada, en cambio, acerca de la presencia de Ángela Grimau (Ángela Martínez) y Rosa García en la Conferencia. Se trataba de dos "mujeres de preso"s. La primera, viuda de Julián Grimau que había sido ejecutado dos años antes, pronunció un saludo y pidió la revisión del proceso de su marido ${ }^{6}$. La segunda leyó un texto de los presos de Burgos, entre los que se encontraba su esposo. Sus palabras fueron acogidas por la audiencia en pie, con una gran ovación. Además de llevar a la sala la voz de los presos de Burgos, Rosa García hizo entrega a la asamblea de una obra del pintor Agustín Ibarrola 7 .

Tanto el escrito como la pintura habían sido producidos tras las rejas de la prisión de Burgos, burlando el sistema de control penitenciario. Rosa García era el único individuo, la única hebra visible que probaba la conexión que existía entre los presos políticos y una red de apoyo al antifranquismo que era extensa, difusa y resiliente. Las palabras y la pintura que Rosa García hizo llegar a Londres han de considerarse en el marco del notable volumen de textos, imágenes y objetos producidos en las cárceles franquistas que circularon tanto dentro como fuera de las mismas pese a las dificultades y riesgos que ello entrañaba ${ }^{8}$. Si bien se conservan otros escritos y otras imágenes producidas por presos, la tela que es objeto de este artículo es la única de las pinturas originales realizadas por Ibarrola en estos años que hemos podido encontrar por el momento. Su estudio directo nos permite alcanzar algunas conclusiones que, a nuestro juicio, pueden ser de interés para pensar el resto de su producción clandestina en la cárcel.

Agustín Ibarrola había sido detenido el 14 de junio de 1962. Fue torturado durante los interrogatorios y juzgado junto con once detenidos más en el Consejo de Guerra celebrado el 21 de septiembre de $1962^{9}$. Fue condenado a nueve años de cárcel. Ibarrola tenía permiso oficial para pintar en la Prisión Central de Burgos, donde cumplió su condena, sin embargo, dado que se trataba de una actividad sujeta al control de los responsables de la prisión, el artista realizó clandestinamente otras pinturas donde abordaba temas relacionados con la represión, la tortura, la cárcel y la lucha antifranquista. Estas piezas lograron salir de la cárcel y fueron expuestas en diversos países europeos gracias al apoyo brindado al antifranquismo por una red de organizaciones, colectivos e individuos que enmarcaban sus demandas en la defensa de los derechos humanos y de la amnistía para los presos políticos ${ }^{10}$.

Las movilizaciones que reclamaban la amnistía para los presos políticos y los exiliados del franquismo habían ido tomando cuerpo especialmente desde inicios de los años cincuenta. En 1952 el Partido Comunista de España (PCE) había iniciado una campaña por la amnistía para los presos y exiliados políticos. Irene Abad ha señalado cómo esto, combinado con otros factores, marcó un punto de inflexión en las movilizaciones y actuaciones en relación con los presos: de tener como principales protagonistas a miembros del entorno familiar y estar orientadas por necesidades puntuales surgidas en el entorno de sus presos, se pasó a un apoyo social más amplio

${ }^{4}$ EFE: “El 'British Appeal for Amnesty in Spain' acuerda la felicidad de los españoles”. En: $A B C$, Madrid, 30-III1965: 42

5 Sobre este concepto, su desarrollo y su importancia en el antifranquismo, especialmente en el movimiento pro amnistía, así como sobre el papel fundamental desempeñado por las mujeres en el mismo véase Abad, 2012: 28-34.

${ }^{6}$ La detención, tortura, condena y ejecución de Grimau en 1963 movieron a la acción y la lucha por la amnistía a nivel internacional. Desde entonces, Ángela Grimau sería una figura muy importante en las campañas pro amnistía. Sobre el impacto mediático de la ejecución de Grimau véanse Rodríguez, 2007; Balsebre / Fontova, 2014: 219-289.

7 ED: "Se celebra en Londres importante conferencia europea de solidaridad con el pueblo español". En: España republicana, La Habana, 15-IV-1965: 13.

8 Sobre las manifestaciones de cultura escrita clandestina en las cárceles franquistas, véase la publicación resultante de la exposición Letras clandestinas, 1939/1976 (Imprenta Municipal de Madrid, 28 de abril — 30 de octubre de 2016), Martínez, 2016.

${ }^{9}$ Las demás personas juzgadas fueron Ramón Ormazábal, Gregorio Rodríguez, María Dapena, Gonzalo José Villate, Vidal de Nicolás, Antonio Giménez Pericás, Andrés Pérez, José María Ibarrola y Enrique Múgica. Se puede encontrar un estudio más detallado sobre estas detenciones y, especialmente, sobre el caso de Ibarrola en De Haro, 2016: 299-302.

${ }^{10}$ La labor artística clandestina de Ibarrola en el Penal de Burgos, así como la circulación y exposición de estas pinturas ha sido estudiada por De Haro, 2016: 299-316. 
y a reclamar el fin de la represión y la libertad del conjunto de presos políticos españoles ${ }^{11}$. No cabe duda de que la defensa de los derechos humanos podía encontrar una amplia resonancia en la sociedad ya que permitía evitar tanto enmarcados asociados por muchos con épocas pasadas, como acusaciones de partidismo, tan propias de la Guerra Fría. Esto suponía cambiar el marco interpretativo que daba sentido a la acción colectiva en el seno del movimiento antifranquista ${ }^{12}$. En efecto, en lugar de cuestionar la legitimidad del régimen, de reclamar una España republicana o de hacer hincapié en la causa antifascista, en lugar de defender las ideas políticas de los presos o de posicionarse en uno de los bloques de la Guerra Fría, las campañas pro amnistía denunciaban que en España no se respetaban los derechos recogidos en la Declaración Universal de los Derechos Humanos aprobada por la Asamblea General de las Naciones Unidas a finales de 1948. Esto revestía una especial significación toda vez que la actitud de las Naciones Unidas hacia la España franquista había ido cambiando desde 1950: el país comenzó a incorporarse a organismos adscritos en 1951 e ingresaría en la ONU en 1955. Por su parte, las organizaciones pro amnistía que comenzaron a fundarse entonces siempre buscaron que sus apoyos fueran diversos ideológicamente, e investigarían y denunciarían agresiones a los derechos humanos bajo cualquier tipo de gobierno, comunistas, anticomunistas o no alineados ${ }^{13}$.

Cuando el 11 de junio de 1958 el periódico francés Le Figaro publicó una entrevista donde Franco declaraba que en España ya sólo se realizaban detenciones por delitos de Derecho Común, la irritación de los presos políticos y sus familias hizo que se reduplicaran los esfuerzos y movilizaciones por la amnistía ${ }^{14}$. Las campañas tuvieron eco dentro y fuera de España. En el caso de Reino Unido esto llevó a la aparición de Appeal for Amnesty in Spain (AAS) en 1959 ${ }^{15}$. Esta organización respondía a un modelo frentepopulista y contaba con el apoyo de reconocidas figuras públicas como, por ejemplo, el periodista John Arlott, el historiador Hugh Trevor-Roper, el liberal Jeremy Thorpe, el escultor Henry Moore, el compositor Benjamin Britten o el pintor Michael Ayrton. Con todo, a pesar de que afirmaba no responder a una ideología política concreta y de que reunía apoyos de los más variados colores políticos, su actividad siempre fue vista como parte de las políticas del Partido Comunista de Gran Bretaña (CPGB) ${ }^{16}$.

AAS se encargó de organizar la Conferencia de Europa occidental para la amnistía de los presos y exiliados políticos españoles a la que llegaron la carta de los presos de Burgos y la pintura de Ibarrola (fig. 1). Antes de esta conferencia se habían celebrado otras similares en distintos países. Concretamente en Sâo Paulo (enero, 1960), en Montevideo (enero, 1961) y París (marzo, 1961). Mientras que las dos primeras eran de ámbito latinoamericano y reclamaban la amnistía para los presos y exiliados políticos de España y Portugal, la reunión celebrada en París se ocupaba únicamente del caso español. Según rememora Yvette Lucas, antigua presidenta del Comité Toulousain pour l'Espagne formado precisamente adoptando los objetivos de la conferencia parisina, la conferencia celebrada en Londres el 28 de marzo de 1965 fue la segunda de las conferencias de Europa occidental por España celebradas en territorio europeo ${ }^{17}$.

11 Abad, 2004: 17-20; 2012.

12 Sobre el cambio en el marco interpretativo que llevó a cabo Appeal for Amnesty in Spain y el papel desempeñado por las imágenes, véase De Haro, 2014: 107-120.

13 A modo de ejemplo, cabe mencionar cómo, para lograr este equilibro, Amnesty International (fundada por Peter Benenson en Londres en 1961) hizo que los grupos locales que se ocupaban de las causas de los prisioneros de conciencia identificados por la organización siempre trabajaran a la vez en los casos de tres personas a la vez: una encarcelada por un gobierno comunista, otra por un anticomunista y otra por uno no alineado. Neier, 2012: 189.

14 Abad, 2012: 132.

15 Esto coincidía con el vigésimo aniversario del final de la Guerra Civil, como vemos, los cambios en el enmarcado de las movilizaciones no se llevaron a cabo sustituyendo unos marcos de interpretación por otros, sino que, en casos como éste, se puede hablar, más bien, de una superposición de marcos.

${ }^{16}$ Sir Stephen Sedley que estuvo implicado en AAS, siempre ha defendido la independencia de la organización afirmando que, a pesar de la militancia comunista de algunas de sus figuras principales, ni dependía ni actuaba como pantalla del CPGB. Testimonio de Sir Stephen Sedley en conversación con la autora, Oxford, 4-III-2014.

17 Yvette Lucas, “Le Comité toulousain pour l'Espagne (1965-1975), dix années de solidarité et d'actions", intervención en el coloquio de Nérac celebrado el 7-8-III-2009. Texto disponible en "Les conférences de MER47: Yvette 


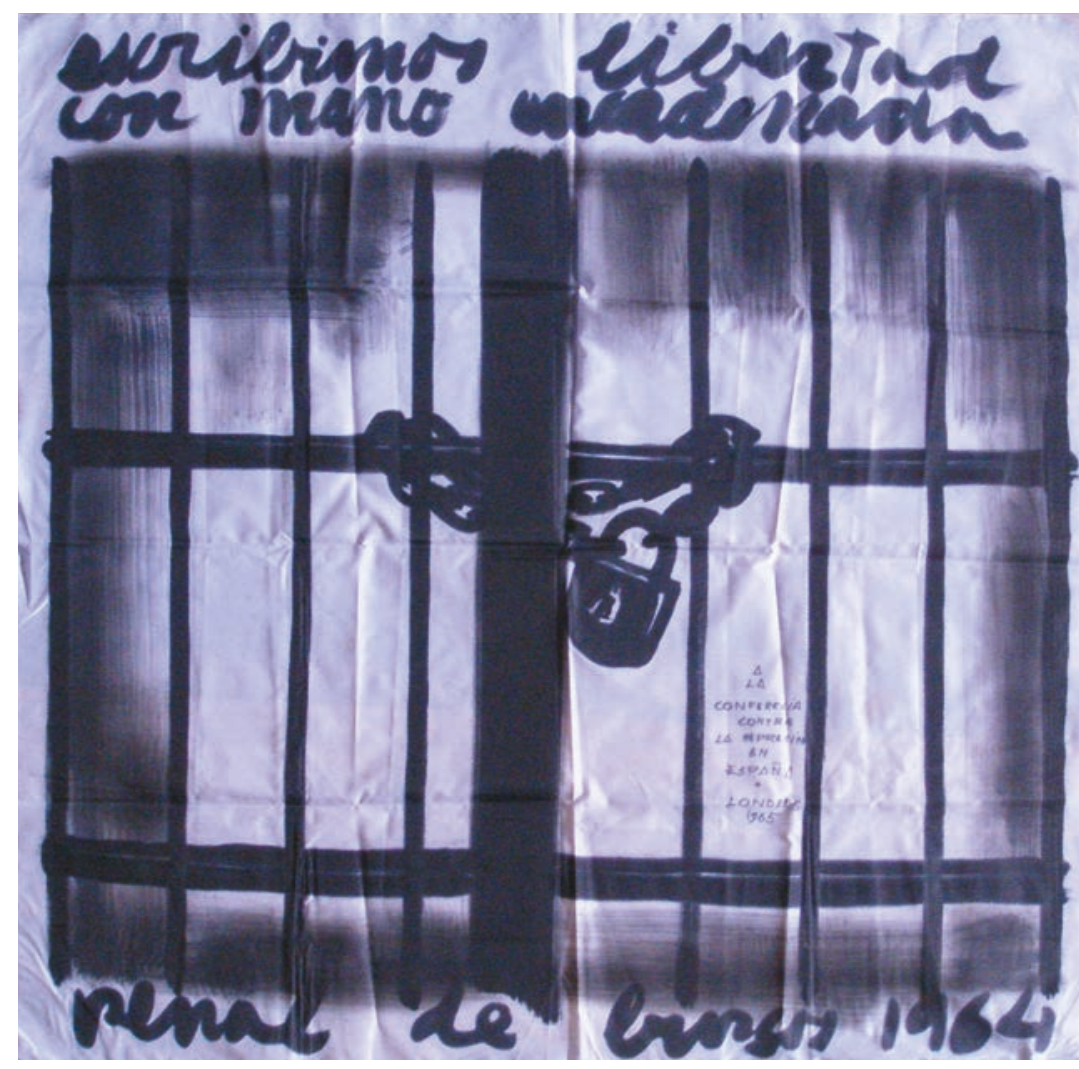

Fig. 1. Agustín Ibarrola, Sin titulo ["Escribimos libertad con mano encadenada / penal de Burgos 1964"], sin fecha. Tela entregada a la Conferencia de Europa occidental para la amnistía de los presos y exiliados políticos españoles celebrada el 28 de marzo de 1965 en Londres. Colección particular.

Las imágenes en general y el arte en particular desempeñaban un papel relevante en el marco de las actividades de AAS. Era algo que compartía con otras organizaciones similares: las obras de arte que abordaban cuestiones relacionadas con las demandas de la organización contribuían a difundir su mensaje y, cuando se trataba de obras de arte donadas por los artistas para ser vendidas por la organización, demostraban el apoyo obtenido por parte de personalidades conocidas del ámbito cultural que daban algo que podía considerarse como mucho más representativo de sí mis$\operatorname{mos}^{18}$, al tiempo que contribuían a recaudar fondos para la causa ${ }^{19}$. La obra de Picasso había tenido un protagonismo especial en la conferencia celebrada en París en 1961: uno de sus dibujos se había expuesto en la sede y se había reproducido en los materiales del encuentro. Resulta sencillo imaginar la impresión que debió generar entre los asistentes a la Conferencia londinense el hecho de que uno de los envíos llegados desde el Penal de Burgos fuera precisamente una tela pintada por Ibarrola. Era un artista que les debía de ser muy querido; no en vano, la primera vez que se había podido ver un conjunto importante de pinturas realizadas por el artista durante su cautiverio había sido en la muestra organizada por AAS en la St. George's Gallery de Londres en diciembre de 1963.

La tela enviada desde Burgos presentaba rasgos en común pero también diferencias con aquellas pinturas. Las obras expuestas en Londres a finales de 1963 eran, en su mayoría, de pequeño

Lucas", Le blog de Mer47. Memoire de l'exil républicain espagnol en Lot-et-Garonne. En: http://mer47.org/wp/lesconferences-de-mer-47/ [consulta: 4-I-2018].

${ }^{18}$ En este sentido se orientaban las palabras de Michel Ayrton reproducidas en una de las publicaciones de AAS: "To sign an appeal, to write a cheque is relatively easy. But for an artist to give a piece of his own work, a creation of his own, is quite a different matter". "Support from abroad". En: Amnesty for Spanish political prisoners and exiles, Londres, 1961: 10. Papers of Richard Albert Etheridge, Modern Records Centre, University of Warwick (MRC, UW), MSS.202/5/40.

${ }^{19}$ El caso concreto del papel de las imágenes y las obras de arte en AAS se estudia en De Haro, 2014. 


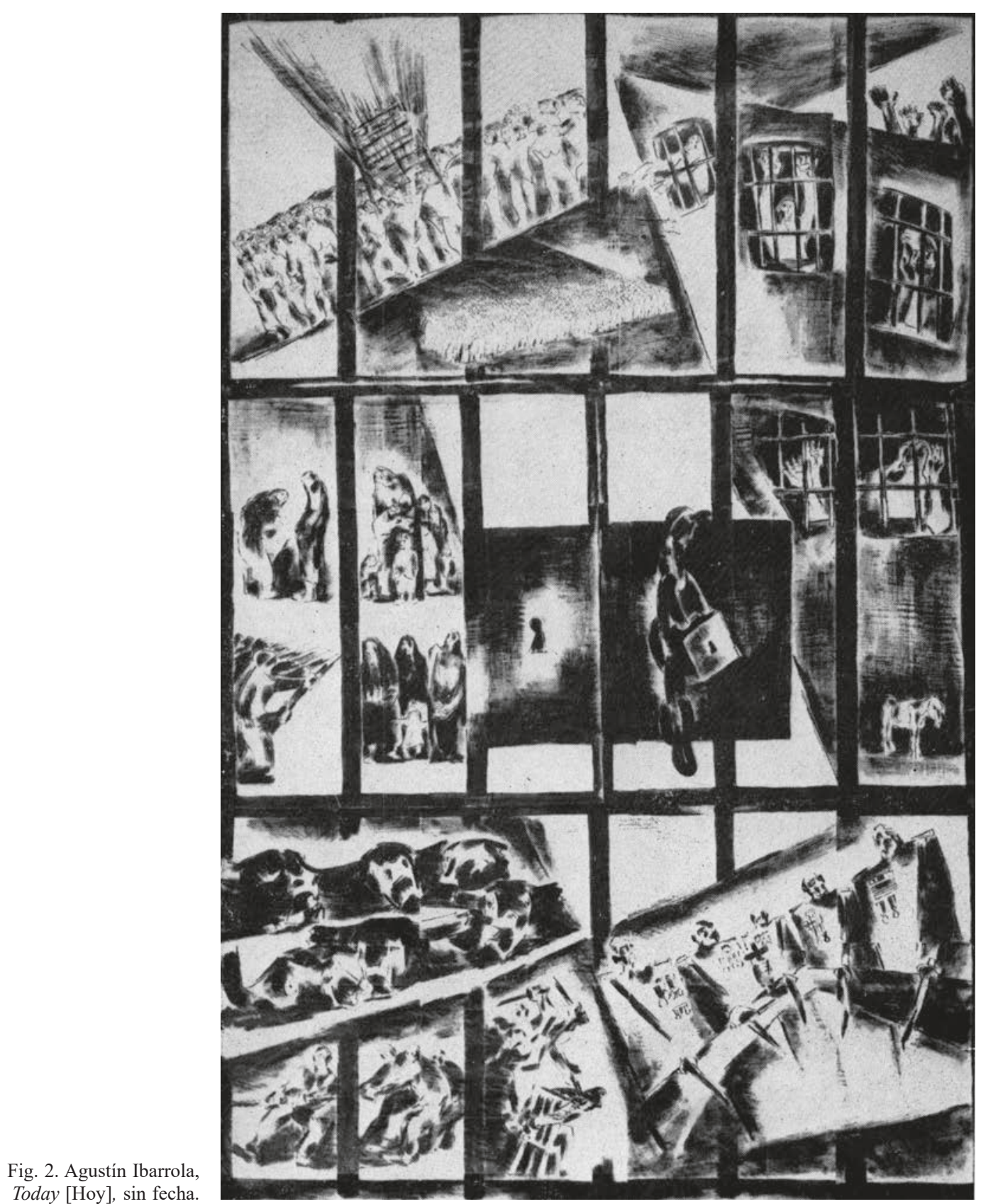

tamaño y estaban realizadas sobre un papel muy delgado. Las piezas de mayor tamaño eran tres paneles titulados Yesterday, Today y Tomorrow que componían una especie de tríptico sobre la España del pasado, del presente y del futuro. Dichos paneles parecían haber sido pintados por partes, de manera que éstas pudieran ser luego ensambladas. En cambio, la obra enviada al encuentro londinense de 1965 estaba realizada sobre una tela de un tamaño considerable $(768 \mathrm{~mm}$ de ancho por $786 \mathrm{~mm}$ de alto) que había sido pintada de una vez, no doblando y desdoblando distintas secciones de la tela. Un envío semejante constituía una demostración de lo que eran capaces de lograr los presos del Penal gracias a su nivel de organización, así como de su valentía. No cabe duda de las dificultades que entrañaba crear las condiciones para desplegar y pintar una tela de este tamaño, más fácil de descubrir y más complicada de ocultar que un papel pequeño 


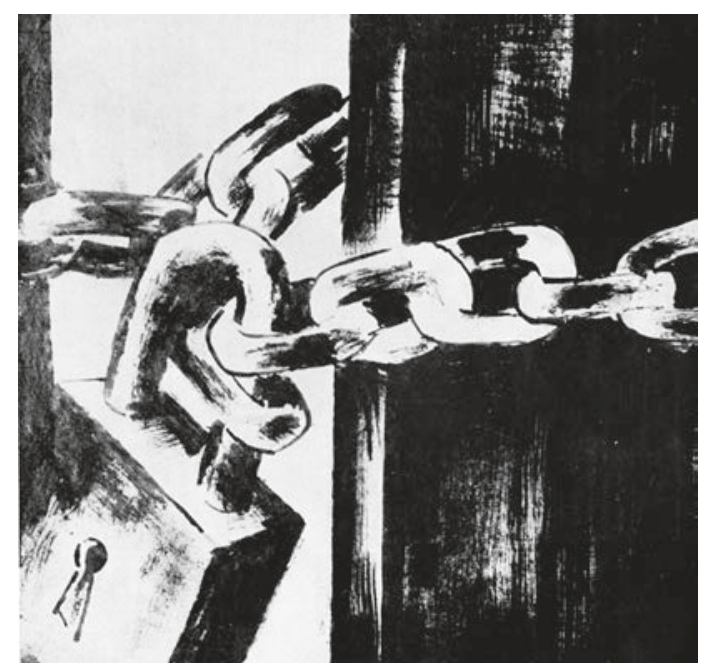

Fig. 3. Agustín

Ibarrola, Franco's prisons [Las prisiones de Franco], sin fecha.
Fig. 4. Agustín Ibarrola, The locks [Los cerrojos / Los candados], sin fecha.

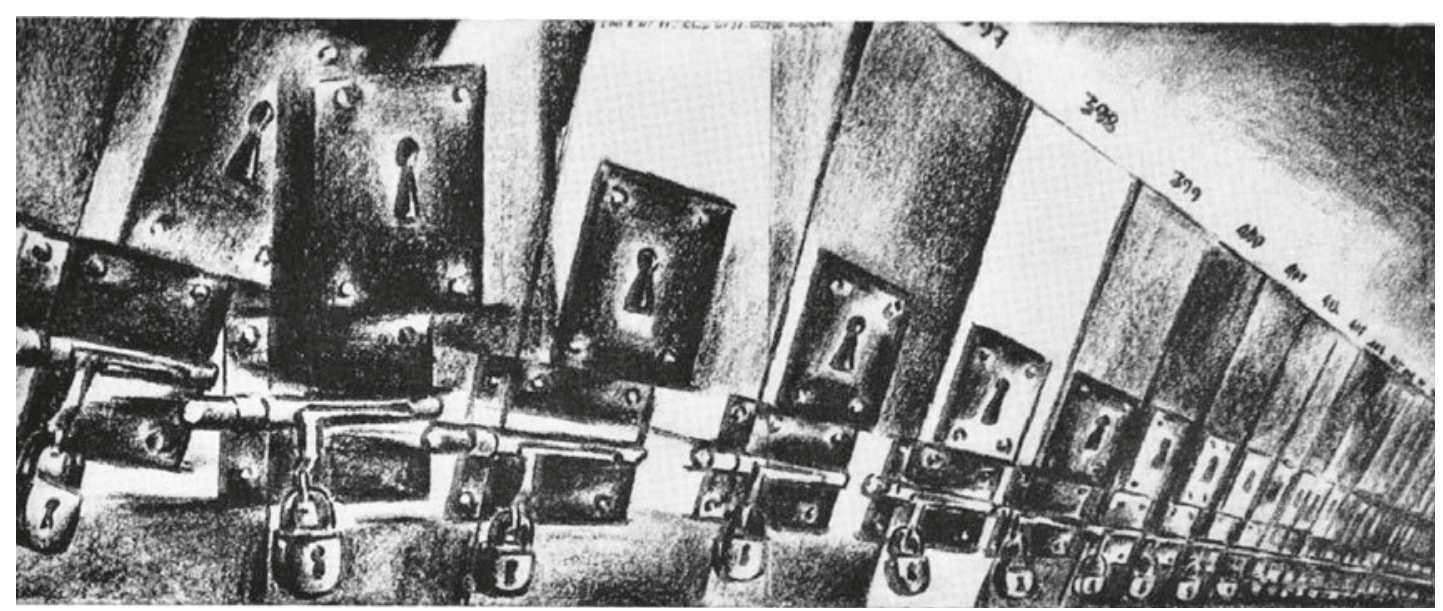

en caso de ser sorprendidos. La precariedad y la urgencia de la clandestinidad explican que la pintura hubiera sido realizada con una gran economía de medios, estaba resuelta con unas cuantas pinceladas rápidas y certeras sobre un soporte sin preparar: una fina tela blanca producida de modo industrial, de fácil deshilachado en sus dos laterales, sobre la que se había aplicado pintura o tinta negra con pincel.

La tela se hacía eco del motivo central de Today, el segundo panel del tríptico: los barrotes de una puerta cerrada y asegurada por una cadena con candado (fig. 2). No resulta extraño que rejas, cerraduras y candados sean un motivo recurrente en las pinturas carcelarias de Ibarrola (figs. 3 y 4), o en escritos de poetas presos como Marcos Ana (Fernando Macarro). De hecho, a veces, como en la tela que nos ocupa, podían ser el único motivo de la imagen, sólo con unas pinceladas dramáticas al fondo. En Today lo rodeaba un mosaico de escenas de movilización de masas, represión, tortura, juicio militar, cárcel y fusilamiento. En lugar de ello, en la parte superior e inferior de la tela ofrecida al Congreso, escritas con el mismo pincel y la misma pintura empleados para la imagen, se leía: "escribimos libertad con mano encadenada / penal de burgos 1964". Esto puede ser interpretado como una nota de esperanza para la lucha antifranquista. De una parte, las cadenas que atan las muñecas de los presos en otras imágenes de Ibarrola muestran su condición y su sufrimiento, pero no les vencen. En una escena de fusilamiento de indudables reminiscencias goyescas, sus brazos desnudos se alzan, unidos por las cadenas y por los (invisibles, pero más sólidos) lazos de la oposición antifranquista, son sus 


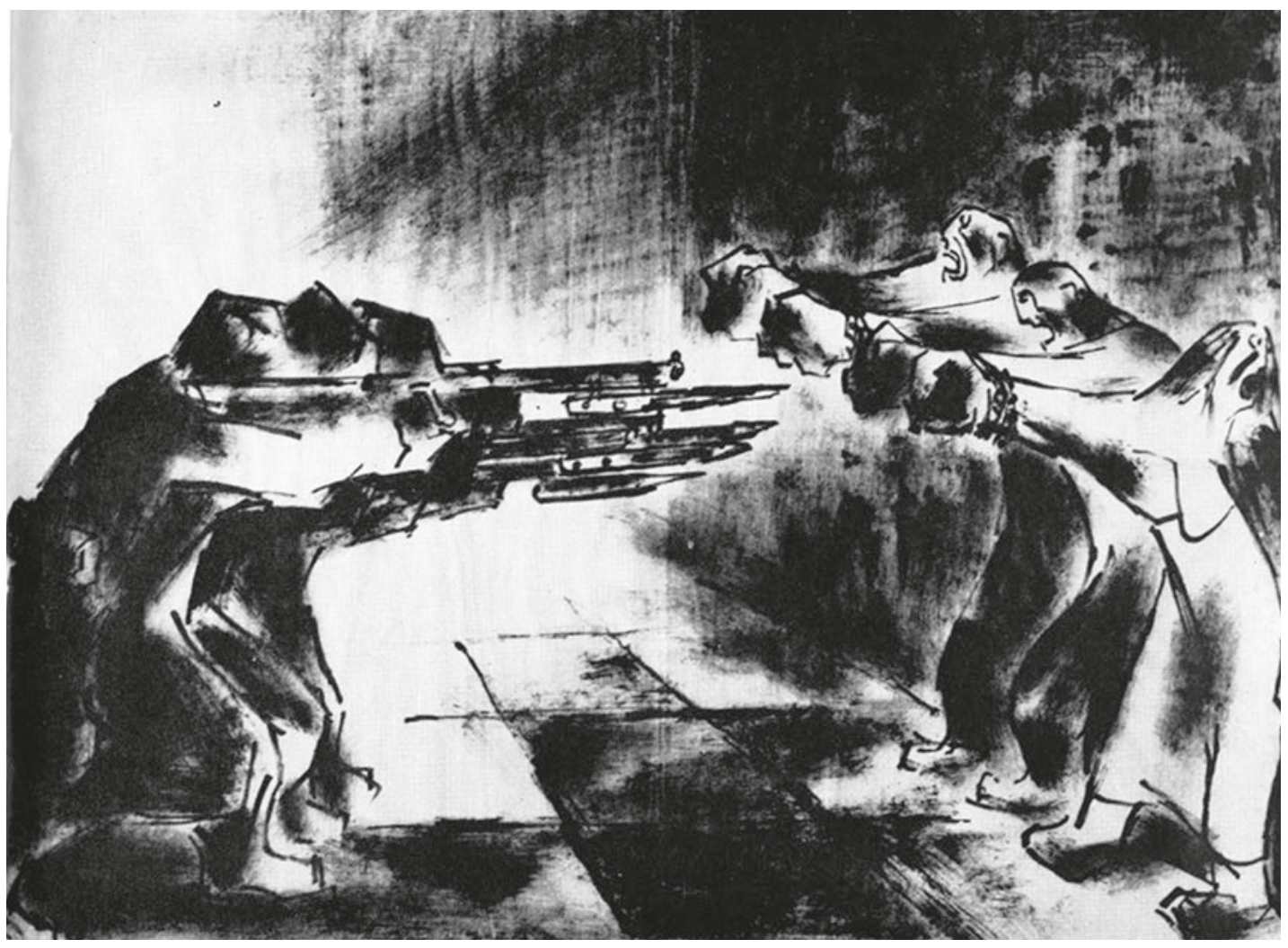

Fig. 5. Agustín Ibarrola, The wall [El muro], sin fecha.

“armas" frente a la represión (fig. 5) ${ }^{20}$. De otra, la frase hace pensar en cómo los antifranquistas creaban espacios de libertad con sus acciones y su lucha incluso cuando sufrían la represión del régimen franquista. Parece lógico este giro combativo en una creación destinada a una conferencia que luchaba por la amnistía.

Estas mismas palabras, en blanco sobre un fondo negro (como si una luz de esperanza las hubiera abierto en la negrura de la cárcel), sin imágenes, eran las protagonistas de un documento (¿un pequeño cartel o panfleto, quizá?) producido en la cárcel de Burgos (fig. 6). Parecían tener, pues, una significación especial para los presos. Además, podían traer a la memoria las palabras de muchos de los poetas que habían estado o aún se encontraban en la cárcel de Burgos como era el caso de Marcos Ana o de Vidal de Nicolás ${ }^{21}$. Junto con esto, también podían resonar con las primeras líneas del célebre poema de Paul Eluard "liberté, j'écris ton nom" que se publicó de forma clandestina en la Francia ocupada en 1942, llamando a la resistencia. El texto, traducido a varias lenguas, fue impreso en hojas lanzadas desde aviones británicos sobre el territorio francés. Cabe pensar que quizá no fuera coincidencia que se hubieran elegido estas palabras para una tela destinada a ser presentada en Londres. A estas líneas se sumaba una dedicatoria

${ }^{20}$ Como ya se ha indicado, se desconoce el paradero de las obras originales. En el caso de las que se reproducen en las figuras 2 a 5 los títulos se han tomado de los que aparecen en folleto de la exposición Drawings from Burgos jail en City Art Gallery Annexe (Manchester, enero 1964). Las imágenes de las figuras 2 y 3 proceden de la publicación que acompañó a la exposición de obras de Ibarrola en la Galleria del Sottopassaggio (Bologna, abril-mayo 1964), mientras que las de las figuras 4 y 5 proceden de Agostin Ibarrola. Tekeningen uit de gevangenis van Burgos met gedichten van Marcos Ana en Vidal de Nicolas, Amsterdam: Van Ditmar, s/f [1965].

${ }^{21}$ AAS había publicado from Burgos jail, una traducción de poemas de ambos junto con reproducciones de obras pintadas por Ibarrola en la cárcel: Ana / de Nicolás / Ibarrola, 1964. 


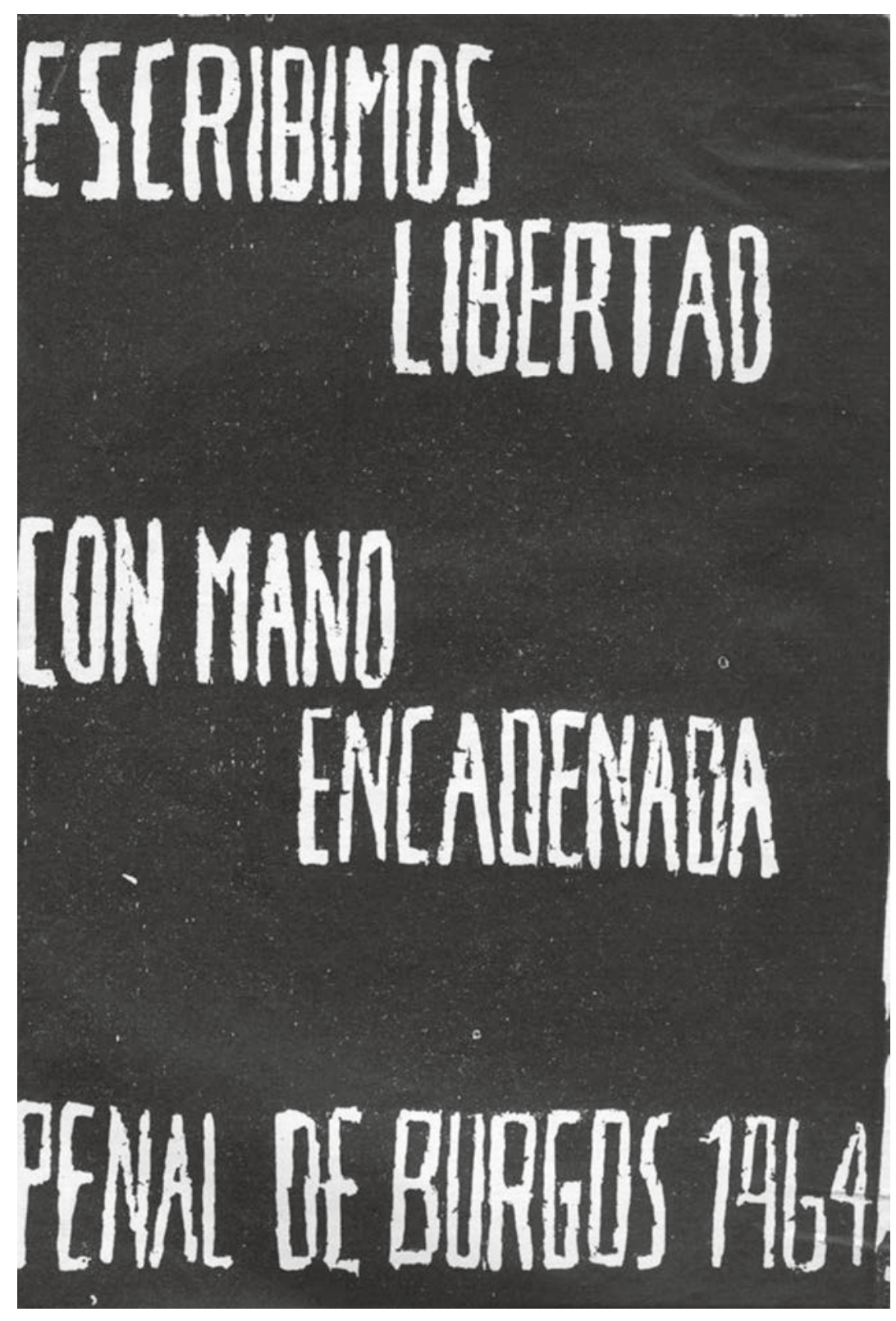

Fig. 6. Cartel producido por los presos del Penal de Burgos, sin fecha. AHPCE.

específica a la Conferencia que, probablemente, había sido escrita con un rotulador negro con posterioridad a la salida de la pintura de la cárcel. Probablemente se tratara de una medida de seguridad (al igual que el hecho de que la pintura no estuviera firmada por el artista) en caso de que la tela fuera descubierta antes de llegar a su destino.

El tamaño de esta pintura parece anunciar el de algunas de las que se expondrían en muestras como la celebrada en la galería Epona de París en junio de 1965. Estas telas, aún de mayor tamaño que la enviada a Londres, no sólo causaban un impacto en los visitantes por los temas representados, sino que hacían preguntarse por cómo había sido posible realizarlas y sacarlas de la cárcel ${ }^{22}$. No sabemos exactamente el sistema por el que estas pinturas salieron de la cárcel de

22 Sobre esto véase De Haro, 2016: 299-300, 313-314. 
Burgos, pero hay indicios de que, en fechas cercanas a la celebración de la Conferencia, los presos tuvieron que buscar un sistema alternativo para hacer llegar sus envíos. En una nota urgente en clave avisaban de lo siguiente:

Vía (1) recibiréis en esta semana documentos para la Conferencia de Londres y carta para vosotros. Posiblemente irán también un familiar nuestro y abogado amigo para asistir a la Conferencia.

Desde el día de San José se han tomado en la prisión medidas extraordinarias del mayor rigor con nuestros paquetes. [...]

No nos mandéis ya nada POR ESTE PROCEDIMIENTO, ES DECIR NO EMPLEEIS, HASTA NUEVO AVISO, EL SISTEMA DE BOTES. Desde este momento emplearemos únicamente el sistema de salida y recepción por medio de los (3) que trabajan con nosotros ${ }^{23}$.

No es posible saber a qué personas se referían los números porque se desconoce la clave, con todo, de ella se desprende que los presos promovieron la participación de, al menos, dos personas en la Conferencia: un familiar y un abogado. Es posible que el familiar fuera precisamente Rosa García, la esposa de uno de los presos, aunque también podría tratarse del estudiante que asistió al encuentro. Fuera como fuese, el nombre del estudiante y el abogado "llegados expresamente de España" era omitido en las crónicas de la Conferencia publicadas por la oposición "por razones obvias", en ellas se indicaba que estos participantes "dieron a conocer los informes de la situación actual en España, tanto estudiantil como obrera"24. Las crónicas hacían también hincapié en la diversidad ideológica de los participantes y de los apoyos en la lucha por la amnistía y celebraban los lazos existentes entre todos los ámbitos de la oposición, destacando la recepción de mensajes de adhesión como los de los profesores José Luis López Aranguren y Agustín García Calvo, expedientados en febrero de ese año ${ }^{25}$.

Del contenido de la carta de los presos de Burgos también se sigue que anteriormente habían empleado un "sistema de botes" 26 pero que, a la vista del incremento de medidas de control en la cárcel (motivado quizá por buscar evitar que se realizaran envíos y comunicaciones para actos como el de Londres), tan sólo podían confiar en la ayuda de sus colaboradores en la cárcel para realizar y recibir envíos. Probablemente las nuevas medidas de control en la cárcel afectaron a la salida de las pinturas de gran tamaño que se expusieron en París en junio de 1965, que habrían sido enviadas con la ayuda de estos colaboradores. Dado que comparte algunas de sus características es posible que la salida de tela que nos ocupa, si bien realizada antes de que se impusieran las mencionadas medidas extraordinarias, se hubiera hecho con un procedimiento similar, es decir, contando con estos colaboradores dentro de la prisión.

Los orificios que se advierten en las esquinas de la tela y las ligeras manchas que hay en algunos de ellos parecen indicar que estuvo fijada a la pared con puntas metálicas (quizá grapas en un momento y chinchetas o pequeños clavos en otro). En suma, la pieza estuvo expuesta si

${ }_{23}$ Carta de (8) 22-3-1965. Archivo Histórico del PCE. Represión franquista, jacq 901.

${ }^{24}$ Gemio, Waldo, "Conferencia internacional contra la represión en España”. En: Libertad para España, Bruselas, V-1965: 3.

25 “Conferencia del països d'Europa occidental contra la repressió franquista". En: Treball. Organ central del PSU de Catalunya, Barcelona, IV-1965: 4. Junto con López Aranguren y García Calvo, habían sido expedientados también Santiago Montero Díaz y Enrique Tierno Galván. Habían cometido faltas graves según el Reglamento de Disciplina Académica, concretamente "insubordinación contra las autoridades académicas" e "invitación o estímulo, en cualquier forma, de las manifestaciones colectivas de los escolares, dirigidas a la perturbación del régimen normal académico o sindical". En agosto de 1965 la autoridad franquista decidió separar definitivamente de la Universidad a López Aranguren, García Calvo y Tierno Galván, y temporalmente a Aguilar Navarro y Montero Díaz.

${ }^{26}$ Es posible que se tratara de recipientes de doble fondo o de botes de cacao. Gervasio Puerta se refiere a estos y otros sistemas empleados para la transmisión de mensajes en el Penal de Burgos. Él era uno de los responsables de difusión de mensajes, propaganda y ocultación de documentos en la cárcel, así como de la transmisión de mensajes al exterior. En sus memorias también habla de la importancia que para todo ello tenía toda una estructura de colaboradores que estaba formada por presos, personas en los servicios de paquetes y hasta tres funcionarios de prisiones, además de por muchas personas fuera de la cárcel. Puerta, 2011: 102-117. 
bien desconocemos en qué condiciones o por cuánto tiempo. Ahora bien, parece que fue tratada no tanto como una pintura que hubiera que exponer enmarcada cuanto como un póster. Más adelante la tela fue doblada y guardada junto con otra documentación de AAS. Como se ha indicado, la tela no está firmada pero no cabe duda de que la pintó Agustín Ibarrola habida cuenta de su evidente relación con otras pinturas realizadas por el artista en esos años, el hecho de que se conservara junto a otros documentos de AAS, las referencias en diversas publicaciones a la pintura de Ibarrola llevada por Rosa García a la Conferencia organizada por AAS, además del testimonio del propio artista ${ }^{27}$.

Las pinturas realizadas por Ibarrola durante su encarcelamiento en el Penal de Burgos se pudieron ver en Reino Unido, Holanda, Suecia, Italia, Francia, Alemania y España gracias a exposiciones organizadas por las redes de solidaridad del antifranquismo. Pero estas obras llegaron más allá puesto que fueron reproducidas en publicaciones, postales y películas lo cual les permitió trascender el estrecho marco espacial y temporal de la exposición, así como quedar asociadas a la lucha por la amnistía en esos años. Evidencia de la importancia de su alcance y su papel en el imaginario se puede considerar el que la reproducción de una obra de Ibarrola reciba al lector del Libro blanco sobre las cárceles franquistas publicado por Ruedo ibérico en 1976, en él se hablaba de la solidaridad internacional con la campaña pro amnistía ${ }^{28}$. Probablemente el hecho de que fuera un regalo y de que fuera tratada más como un póster o un documento valioso (a los que, en cualquier caso, parecía corresponder permanecer en un ámbito privado), hicieron esta tela quedara fuera de este circuito. Paradójicamente, por esta causa hemos podido realizar este estudio.

\section{BIBLIOGRAFÍA}

Abad, Irene (2004): Las mujeres de presos republicanos: movilización política nacida de la represión franquista (documento de Trabajo 2/2004), Madrid: Fundación $1^{\circ}$ de Mayo.

Abad, Irene (2012): En las puertas de prisión. De la solidaridad a la concienciación política de las mujeres de los presos, Barcelona: Icaria.

Ana, Marcos / de Nicolás, Vidal / Ibarrola, Agustín (1964): from Burgos jail, Londres: Appeal for Amnesty in Spain. Balsebre, Arman / Fontova, Rosario (2014): Las cartas de La Pirenaica. Memorias del antifranquismo, Madrid: Cátedra. De Haro, Noemi (2014): "El papel de las imágenes en Appeal for Amnesty in Spain”. En: Cabañas Bravo, Miguel / Rincón García, Wifredo (eds.): Las redes hispanas del arte desde 1900, Madrid: CSIC, 2014, pp. 107-120.

De Haro, Noemi (2016): "Voces de seda. Las pinturas clandestinas de Agustín Ibarrola (1962-1965)", Archivo Español de Arte, t. LXXXIX, nº 355, julio-septiembre, pp. 299-316.

Faye, Jean Pierre (1965): “Crime de répression continue”. En: Esprit, 341, 9, septiembre, pp. 354-360.

G. Pericás, Antonio (1965): Burgos. Prisión Central, París: Éditions de la Librairie du Globe.

Martínez, Jesús A. (2016): Letras clandestinas, 1939/1976, Madrid: Ayuntamiento de Madrid.

Neier, Aryeh (2012): The international human rights movement: a history, Princeton: Princeton University Press.

Puerta, Gervasio (2011): Palomas tras las rejas. Recuerdos de un luchador antifranquista, presidente de la Asociación de Expresos, Madrid: Endymion.

Rodríguez, Nuria (2007): “La repercusión del caso Grimau en la prensa española e internacional”. En: Bueno, Manuel (ed.): Comunicaciones del II Congreso de Historia del PCE. De la resistencia antifranquista a la creación de IU, Madrid: FIM, pp. 1-20.

Suárez, Ángel / Colectivo 36 (1976): Libro blanco sobre las cárceles franquistas, 1939-1976, París: Ruedo Ibérico.

Fecha de recepción: 09-I-2018

Fecha de aceptación: 08-VI-2018

27 Estos documentos de AAS así como la tela se encuentran en una colección particular. Una fotografía de la pintura fue enviada al artista que confirmó su autoría en octubre de 2016.

28 En realidad, y en consonancia con nuestro argumento, en el libro de Ruedo ibérico se reproduce una reproducción puesto que se indica que la imagen se ha extraído del libro Burgos. Prisión Central (G. Pericás, 1965). Suárez/ Colectivo 36, 1976: s/p. 